This article was downloaded by: [CAS Consortium]

On: 11 May 2009

Access details: Access Details: [subscription number 909168890]

Publisher Taylor \& Francis

Informa Ltd Registered in England and Wales Registered Number: 1072954 Registered office: Mortimer House, 37-41 Mortimer Street, London W1T 3JH, UK

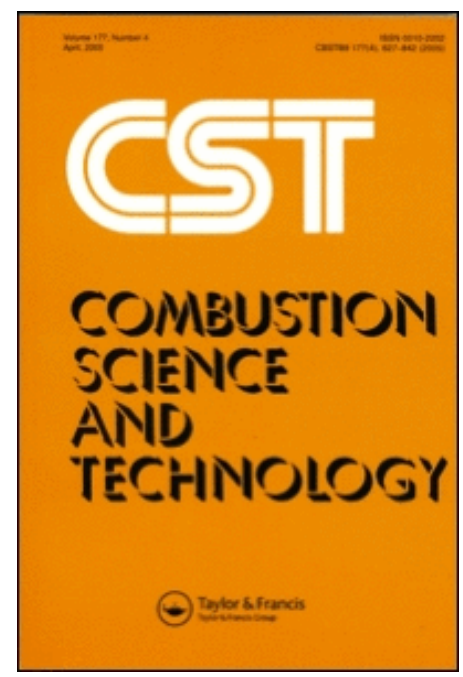

Combustion Science and Technology

Publication details, including instructions for authors and subscription information:

http://www.informaworld.com/smpp/title content=t713456315

\title{
AN EXPERIMENTAL STUDY ON FLAME PROPAGATION IN CORNSTARCH DUST CLOUDS
}

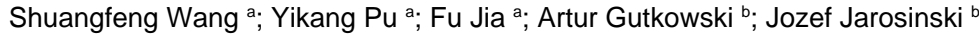

a National Microgravity Laboratory, Institute of Mechanics, Chinese Academy of Sciences, Beijing, China ${ }^{b}$

Department of Heat Technology and Refrigeration, Technical University of Lodz, Lodz, Poland

Online Publication Date: 01 December 2006

To cite this Article Wang, Shuangfeng, Pu, Yikang, Jia, Fu, Gutkowski, Artur and Jarosinski, Jozef(2006)'AN EXPERIMENTAL STUDY ON FLAME PROPAGATION IN CORNSTARCH DUST CLOUDS',Combustion Science and Technology,178:10,1957 — 1975

To link to this Article: DOI: $10.1080 / 00102200600790979$

URL: http://dx.doi.org/10.1080/00102200600790979

PLEASE SCROLL DOWN FOR ARTICLE

\footnotetext{
Full terms and conditions of use: http://www.informaworld.com/terms-and-conditions-of-access.pdf

This article may be used for research, teaching and private study purposes. Any substantial or systematic reproduction, re-distribution, re-selling, loan or sub-licensing, systematic supply or distribution in any form to anyone is expressly forbidden.

The publisher does not give any warranty express or implied or make any representation that the contents will be complete or accurate or up to date. The accuracy of any instructions, formulae and drug doses should be independently verified with primary sources. The publisher shall not be liable for any loss, actions, claims, proceedings, demand or costs or damages whatsoever or howsoever caused arising directly or indirectly in connection with or arising out of the use of this material.
} 


\title{
AN EXPERIMENTAL STUDY ON FLAME PROPAGATION IN CORNSTARCH DUST CLOUDS
}

\author{
SHUANGFENG WANG* \\ YIKANG PU \\ FU JIA
}

\author{
National Microgravity Laboratory, Institute of \\ Mechanics, Chinese Academy of Sciences, \\ Beijing, China
}

\section{ARTUR GUTKOWSKI JOZEF JAROSINSKI}

\author{
Department of Heat Technology and Refrigeration, \\ Technical University of Lodz, Lodz, Poland
}

Following the quantitative determination of dust cloud parameters, this study investigates the flame propagation through cornstarch dust clouds in a vertical duct of $780 \mathrm{~mm}$ height and $160 \times 160 \mathrm{~mm}$ square cross section, and gives particular attention to the effect of small scale turbulence and small turbulence intensity on flame characteristics. Dust suspensions in air were produced using an improved apparatus ensuring more uniform distribution and repeatable dust concentrations in the testing duct. The dispersion-induced turbulence was measured by means of a particle image velocimetry (PIV) system, and dust concentrations were estimated by direct weighing method. This quantitative assessment made it possible to

Received 4 October 2005; accepted 14 March 2006.

The work reported here was sponsored by the Knowledge Innovation Major Project of Chinese Academy of Sciences (CAS) under grant number KJCX2-SW-L05. One of the authors, Artur Gutkowski, was financially supported by the Marie Curie Transfer of Knowledge Project (grant No. ECHIRA NR 509849) during his stay at the National Microgravity Laboratory, CAS.

*Address correspondence to sfwang@imech.ac.cn 
correlate observed flame behaviors with the parameters of the dust cloud. Upward propagating dust flames, from both closed/open bottom end to open/closed top end of the duct, were visualized by direct light and shadow photography. From the observation of propagation regimes and the measurements of flame velocity, a critical value of the turbulence intensity can be specified below which laminar flame propagation would be established. This transition condition was determined to be $10 \mathrm{~cm} / \mathrm{s}$. Laminar flames propagated with oscillations from the closed bottom end to the open top end of the testing duct, while the turbulent flames accelerated continuously. Both laminar and turbulent flames propagated with steady velocity from the open bottom end to the closed top end of the duct. The measured propagation velocity of laminar flames appeared to be in the range of $0.45-0.56 \mathrm{~m} / \mathrm{s}$, and it was consistent with the measurements reported in the literature. In the present experimental study, the influence of dust concentration on flame propagation was also examined, and the flame propagation velocity was found weakly sensitive to the variations in dust concentration. Some information on the flame structure was revealed from the shadow records, showing the typical heterogeneous feature of the dust combustion process.

Keywords: cornstarch, dust concentration, dust dispersion process, dust flame, flame propagation, turbulence

\section{INTRODUCTION}

Combustion of dust clouds in air is of great practical importance due to safety problems related to dust explosion hazards, as well as to utilization of solid fuels. Numerous experimental and theoretical studies on the characteristics of dust combustion have been conducted (Krazinski et al., 1979; Jarosinski et al., 1986; Proust and Veyssiere, 1988; Goroshin et al., 1996; Eckhoff, 1997; Han et al., 2001; Dreizin et al., 2002). Nevertheless, knowledge of the fundamental mechanism of flame propagation in dust-air mixtures is still far from sufficient. Among several great obstacles to dust combustion research, the most outstanding one may be the special experimental difficulties in generating a uniform and stable dust suspension with repeatable dust concentration, and understanding the influence of the state of dust-air mixtures on flame propagation.

In the experimental study of dust combustion, dust particles must be suspended in the air to form a combustible dust cloud. This prerequisite is accomplished by a process called dust dispersion. The structure of the 
dust clouds produced may vary from one apparatus to the next, depending on factors such as the dispersion method and vessel geometry. It appears that the basic question is perhaps not merely how to produce an experimental dust cloud, but rather whether a definition of the cloud states can be given. If quantitative information on the state of a dust cloud (dust concentration, dynamic state, etc.) is obtained, one can correlate the observed flame propagation behaviors with this state, and correlate experimental data from different workers who have used different apparatus. Unfortunately, comparatively little quantitative knowledge exists about dust dispersion processes and the resulting states of the cloud. Herein lies an important reason why the limited experimental results of dust flame propagation are often apparatus dependent and contradict each other in the literature.

The main goal of the present study was to determine quantitatively the parameters of the dust-air mixture produced by flow with small scale turbulence and small turbulence intensity, and to observe flame propagation in this dust cloud. In an introduced dispersion mechanism, the features of dispersion-induced turbulence, dust concentrations and their variations with time were measured in a vertical duct. The upward cornstarch dust flame, which propagated from the closed bottom to the open top, or from the open bottom to the closed top of the testing duct, was examined through photographic records. Based on the quantitative experimental results, the effects of turbulence and dust concentration on flame propagation were discussed.

\section{EXPERIMENTAL DETAILS}

A simplified schematic of the experimental system is shown in Figure 1. Its central part is a vertical duct of $780 \mathrm{~mm}$ height and $160 \times 160 \mathrm{~mm}$ square cross-section, made of glass in order to obtain visualization of the combustion processes and dust particles (illuminated by a laser light sheet) in dust dispersion experiments. The newly designed dispersion mechanism consists of a dust cloud generator and an airflow feeder with pressure controller. The generator, including a porous metallic plate (of $3 \mathrm{~mm}$ thickness, $20-50 \mu \mathrm{m}$ pore size) and an air chamber of the same cross section as the duct, is downward detachable from the duct at a given time by means of an electromagnet controlling system. With the condition of the duct top open, compressed air was introduced through the porous plate producing small scale jets to disperse the dust particles. 


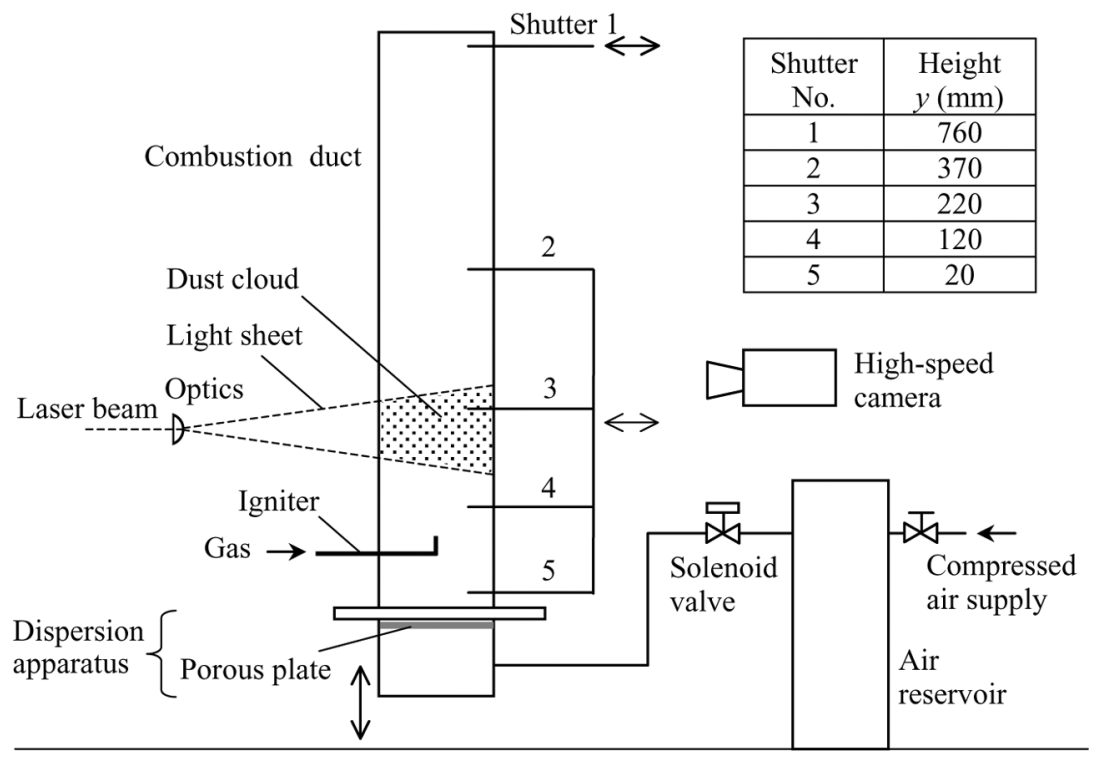

Figure 1. Experimental setup.

Ignition of the dust-air mixtures was achieved by a device resembling a cigarette lighter. A spark with very small energy ignited a small amount of butane-air mixture, and then the gas flame ignited the dust clouds. Cornstarch $\left(\mathrm{C}_{6} \mathrm{H}_{10} \mathrm{O}_{5}\right)$ was used as the fuel. The particles were nearly spherical in shape with a mass mean diameter of $14 \mu \mathrm{m}$.

Three sets of experiments were performed in the present study. The first two were devoted to the measurements of dispersion-induced turbulence and dust concentration (without ignition), respectively, and the third to flame propagation observation. The flames propagated upwards in both cases: from the closed end of the duct (at the bottom) to the open end (at the top), and from the open end to the closed end.

The experimental procedure was as follows. Dust particles were evenly distributed on the fine porous plate at the bottom of the duct. The dispersion process began with the opening of a solenoid valve that connected the dust cloud generator and a compressed air reservoir when the top end of the duct was open. The dust suspension flowed within the duct up to the top end. When the duct was completely filled with a dust cloud, a time controlling system stopped the airflow (the end of dust dispersion). For the case of flame propagation from the lower open end up 
to the closed end, it also closed the shutter at the top end and separated the dust cloud generator from the bottom of the duct simultaneously. In order to examine the influence of dispersion-induced turbulence on flame propagation, the ignition time was delayed by 0.5-3.2 s from the end of dispersion. After the delay, the dust-air mixture was ignited above the bottom end of the duct by the igniter. Thus, the dust flame propagated from the closed bottom end up to the open top end of the duct, or from the open bottom to closed top.

The determination of the feature of dispersion-induced flow was accomplished using a particle image velocimetry (PIV) measurement system. The flow was seeded by the cornstarch dust particles themselves, which were illuminated by a laser light sheet. The movement of dust particles was recorded by a high-speed camera at $100 \mathrm{frames} / \mathrm{s}$, and was subsequently analyzed using a digital image processing system for the quantitative measurements of instantaneous particle velocities. The field of view in the PIV measurements was $40 \times 30 \mathrm{~mm}$. Because of its strongly nonstationary nature, it is necessary to utilize the ensemble average method to determine statistical properties of the dispersion induced turbulence (Hinze, 1975; Pu et al., 1989). More than 90 runs of dust dispersion experiment were repeated. For each test, instantaneous velocity fields at different times relative to the end of dust dispersion were acquired by PIV. The ensemble statistics were constructed by averaging the instantaneous measurements at corresponding times and positions over the various tests.

For the dust concentration measurements, four other horizontal shutters were installed below the topmost one along the height of the duct. These shutters slid into the duct simultaneously at a certain time after the end of the dispersion process, and divided the interior space into four sections. The mean concentration was evaluated by weighing dust particles settled on the shutters with an overall accuracy of $0.01 \mathrm{~g}$. In this way, variation of dust concentration along with the duct and with time can be estimated.

The experimental apparatus was established so as to allow visualization of flames. Two kinds of photographic records were performed: self emitted light and shadow method records. The former was used to obtain the flame propagation over a distance of about $350 \mathrm{~mm}$. For the shadow observation, two opposite windows of optical glass (of $150 \mathrm{~mm}$ diameter and $12 \mathrm{~mm}$ thickness) were installed on the side walls of the duct. The windows were about $300 \mathrm{~mm}$ above the bottom of the duct. Figure 2 


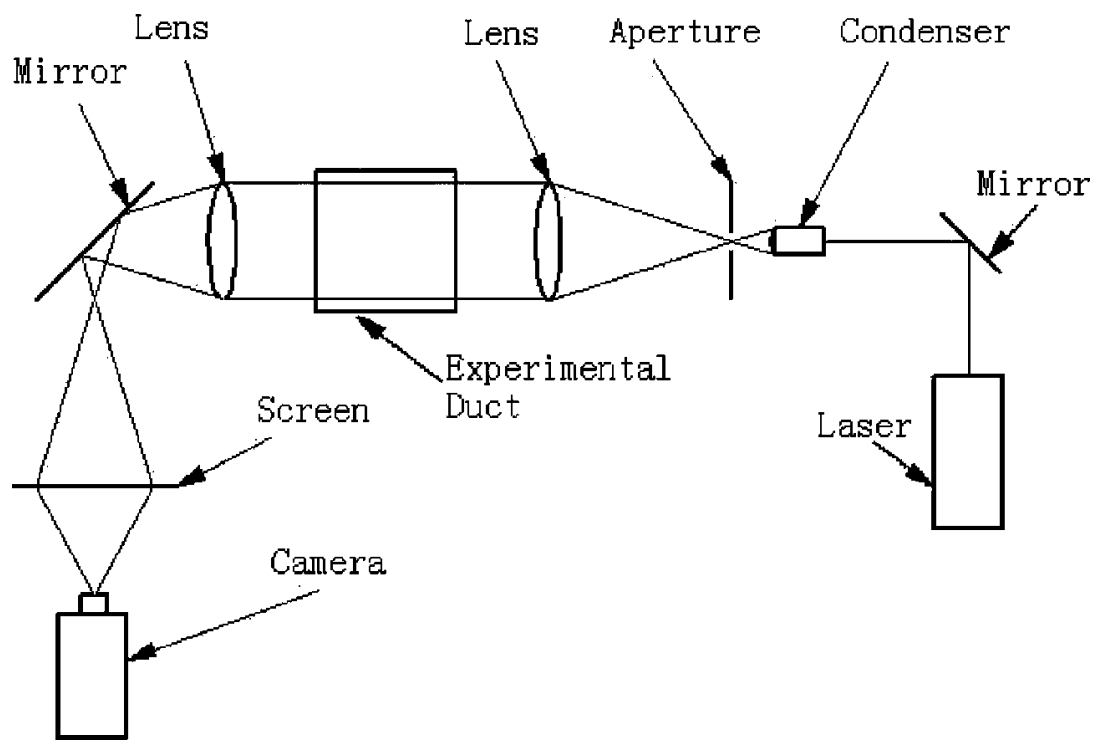

Figure 2. Schematic of the shadow system.

shows how the shadow system employs a $300 \mathrm{~mW}$ laser as light source to produce flame shadow. In both methods, the flame propagation was recorded by the high-speed camera with framing rate of 250 frames/s.

\section{RESULTS AND DISCUSSION}

The turbulence intensity is expressed by the root-mean-square (RMS) of the instantaneous velocities in horizontal and vertical directions. The results of ensemble average process are given in Figure 3(a) as a function of time, where the data at three typical positions (the central point, lower left corner and upper right corner of the observation window) are displayed and collapse well on one curve. In fact, the RMS instantaneous velocities are also evaluated for many other positions. They appear very similar in values to those illustrated in Figure 3(a), and show the same tendency to decay with time. The time-dependent turbulence intensity (in $\mathrm{cm} / \mathrm{s}$ ) in horizontal direction, $u^{\prime}$, and in vertical direction, $v^{\prime}$, can be matched by the following expressions:

$$
\begin{aligned}
& u^{\prime}=14.17(1+t)^{-0.794} \\
& v^{\prime}=18.87(1+t)^{-0.715}
\end{aligned}
$$




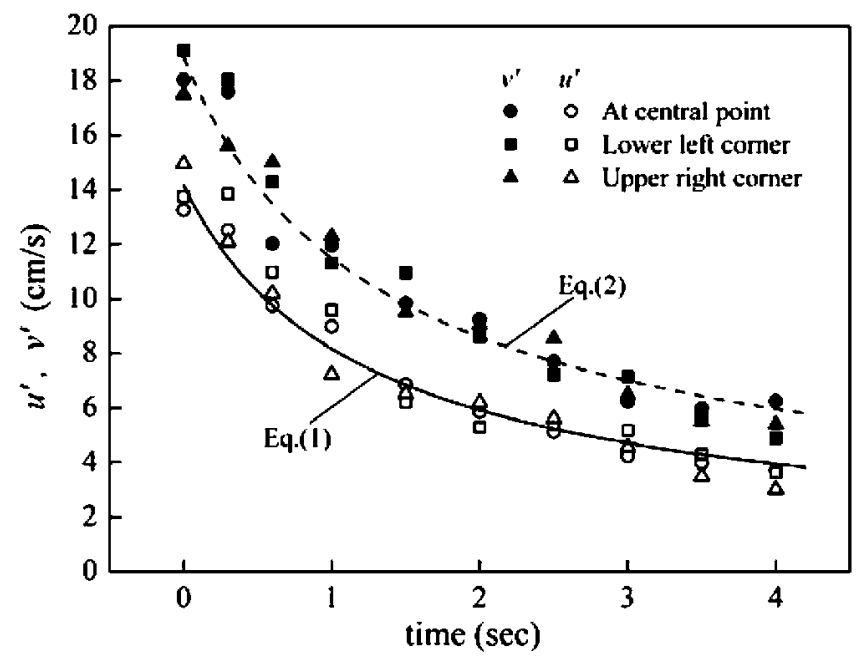

(a)

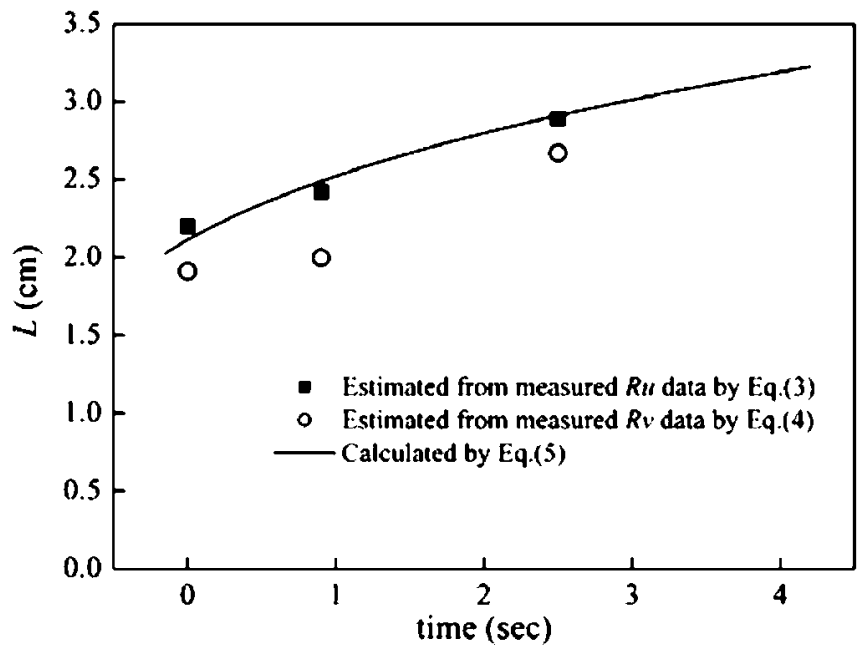

(b)

Figure 3. Parameters of dispersion-induced turbulence as a function of time. (a) Turbulence intensity; (b) integral scale.

In Figure 3(a), it is noteworthy that the maximum value of RMS velocity is less than $20 \mathrm{~cm} / \mathrm{s}$, while for previous dispersion systems this value reached as high as several meters per second ( $\mathrm{Pu}$ et al., 1988, 
1989). The much lower level of velocity fluctuations obtained with the present dispersion mechanism is significant to laminar dust combustion studies. The vertical RMS velocities are systematically higher than the horizontal ones, which obviously reflects the effect of gravity-induced settling of dust particles. Furthermore, the decay of the turbulence intensity is much slower than previous dispersion systems, implying that the dust suspension could be maintained for a longer period of time.

On the basis of the PIV measurements of the instantaneous velocity field, the integral scale of dispersion-induced turbulence, $L$, is readily derived according to its definition:

$$
L_{u}(t)=\int_{0}^{\infty} R_{u}(r, t) d r
$$

or

$$
L_{v}(t)=\int_{0}^{\infty} R_{v}(r, t) d r
$$

where $R_{u}$ and $R_{v}$ are the correlation coefficients of the horizontal and vertical instantaneous velocities, respectively, and $r$ is the distance between two points. For three instants $(t=0,0.9$, and $2.5 \mathrm{~s})$, the results are shown in Figure 3(b). It can be seen that the integral scale deduced from $R_{u}$ conforms with that from $R_{v}$, although the former is a little higher. At the end of the dust dispersion process $(t=0)$, the turbulence has a length scale of about $2 \mathrm{~cm}$. The scale increases with time, and has a value of about $2.8 \mathrm{~cm}$ at $t=2.5 \mathrm{~s}$.

Alternatively, Tamanini and Chaffee (1990) described a method through which information on the integral scale of turbulence can be obtained. The method is based on the definition of $L$ as a function of the turbulence kinetic energy, $k$, and its dissipation, $\varepsilon$, given by:

$$
L=c_{\mu}^{3 / 4} \frac{k^{3 / 2}}{\varepsilon}
$$

In the present dispersion-induced turbulence field, it is reasonable to assume the RMS of the two component velocities in horizontal directions to be equal, which yields the relationship $k=u^{\prime 2}+(1 / 2) v^{\prime 2}$. When Eqs. (1) and (2) are used, and the definition of $\varepsilon(=-\mathrm{d} k / \mathrm{d} t)$ is invoked, the integral length scale can be predicted by Eq. (5) for a value of the constant $c_{\mu}=0.09$, as normally used in the $k-\varepsilon$ model of turbulence. The calculated variation of $L$ with time is also presented in Figure 3(b), 
and the good agreement in the comparison to the experimental measurements is demonstrated.

The determination of dust concentrations was based on a set of five repeated tests. Shown in Figure 4 is the time variation of the mean concentrations at four heights in the duct $(y=70,170,295$, and $565 \mathrm{~mm})$. It is evident that the dust concentration decreases with time and also along the height of the duct. Over the typical propagation distance of dust flames observed in the experiments $(y=100-450 \mathrm{~mm})$, the dust concentration difference can be 2-3 times. Immediately after the end of the dust dispersion process, dust concentrations decrease rather sharply because of the disappearance of dispersion airflow. From $t=0.5 \mathrm{~s}$, however, the variation becomes so gradual that when $t=2.8 \mathrm{~s}$ the dust concentration at $y=565 \mathrm{~mm}$ is still greater than $90 \mathrm{~g} / \mathrm{m}^{3}$, well above the lean flammability limit of cornstarch-air mixtures $\left[70 \mathrm{~g} / \mathrm{m}^{3}\right.$, as reported by Proust and Veyssiere (1988)].

For various ignition delay time, $t_{i}$, defined as a time between the end of dust dispersion and the beginning of ignition, the flame propagated in cornstarch-air mixtures with different initial conditions in terms of turbulence level and dust concentration. Thus by proper selection of ignition delay time, one can change the burning velocity of the dust flame. As it was found in earlier papers (Jarosinski et al., 1993;

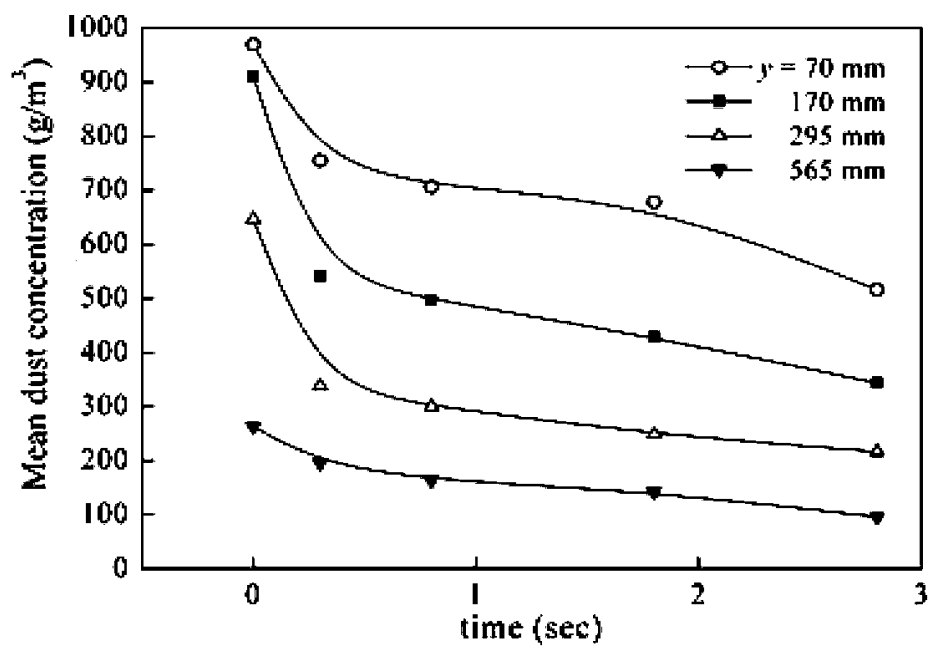

Figure 4. Mean dust concentration as a function of time at four heights of the duct. 
Mazurkiewicz et al., 1993), cornstarch dust-air flames contain intermediate combustion products (i.e., $\mathrm{CO}, \mathrm{H}_{2}, \mathrm{CH}_{4}$ ) and have much lower laminar burning velocity $(5-10 \mathrm{~cm} / \mathrm{s})$ than that propagating in methane-air mixtures. It was also found that the laminar cornstarch dust flame consists of a gaseous flame front (combustion of volatiles) and solid particles reacting deep inside the flame. Only small part of heat is released at the flame front, the remaining part being released far behind it (Jarosinski et al., 2000).

In the case of flame propagation from closed bottom to open top of the duct, the flame front was pushed upward by the expansion of hot combustion gases. The velocity of flame leading point depended in great part on a density difference between the fresh mixture and hot products. Two kinds of flames were observed with the increase of ignition delay time: turbulent flame, and laminar but oscillating flame. The transition occurred approximately at $t_{i}=1.1-1.2 \mathrm{~s}$. Shown in Figure 5(a) are sequences of a typical laminar flame propagation recorded directly by the high-speed camera. It can be seen that the flame front is almost smooth with a parabolic-like form, which is a typical feature of laminar propagating flames in a duct. When the flame reaches about $1 / 4$ of the duct length, it starts to oscillate (jerky movement of the flame) with a frequency of about $10 \mathrm{~Hz}$. The luminosity of the flame also changes periodically with the same frequency. Figure 5(b) shows the flame propagation process for a longer ignition delay time. The scenario is essentially the same as in Figure 5(a), but the oscillatory feature of flame propagation is more obviously illustrated by stages in which the flame is invisible. The frequency of the oscillations has increased to $16 \mathrm{~Hz}$. Oscillating phenomena in dust flame propagation have been observed and discussed by previous researchers (Proust and Veyssiere, 1988; Goroshin et al., 1996). The most probable mechanism of this phenomenon is dust stratification as a result of cooling effect of hot combustion gases by the walls (some analogies can be employed with the tulip flame formation in a closed vessel). Additional effects could be created by the superimposed propagation of two flames: very weak gas (volatiles) flame which is not visible for camera, and luminous dust flame. The flames with long ignition delay time are lean and very slow. Conditions for oscillation of such flames are very favorable. The turbulent flame [Figure 5(c)], observed when the ignition delay time was shorter than $1.1 \mathrm{~s}$, seems to be characterized mainly by an irregular front and a higher propagation velocity. Additionally the total range of the luminous reaction zone is 

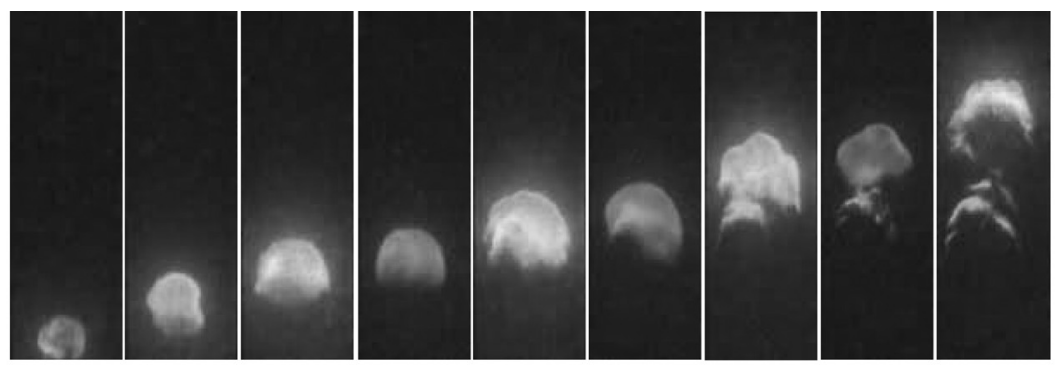

(a)

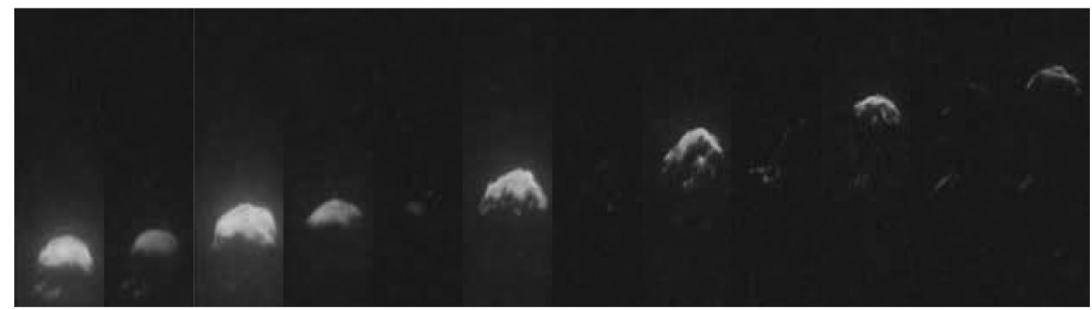

(b)
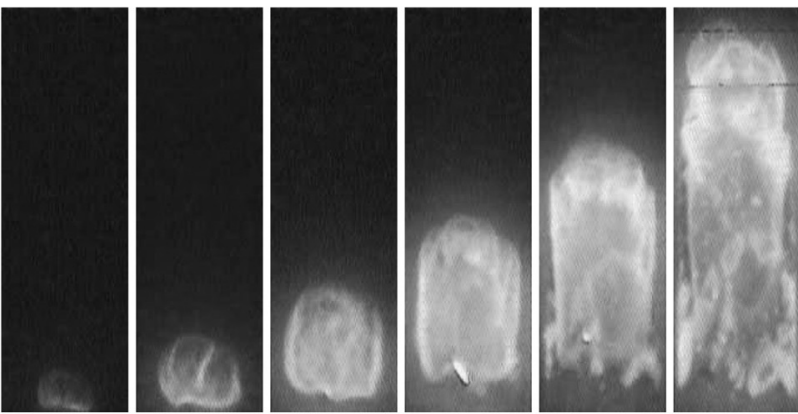

(c)

Figure 5. Photographic records of cornstarch dust flame propagation from closed bottom to open top of the duct. (a) $t_{i}=1.7 \mathrm{~s}$, time interval between pictures $0.052 \mathrm{~s}$; (b) $t_{i}=3.2 \mathrm{~s}$, time interval between pictures $0.04 \mathrm{~s}$; (c) $t_{i}=0.5 \mathrm{~s}$, time interval between pictures $0.04 \mathrm{~s}$.

wider than that for laminar flames. During its propagation, no flame oscillation was noticed.

The flame propagation velocity can be derived from the photographic records through an image analysis process to identify the flame leading edge and then calculating the vertical displacement of the flame. Figure 6 shows the measured flame displacement (from the ignition source) as a function of time for $t_{i}=0.5,1.3,1.8,2.3$, and $3.2 \mathrm{~s}$. It 


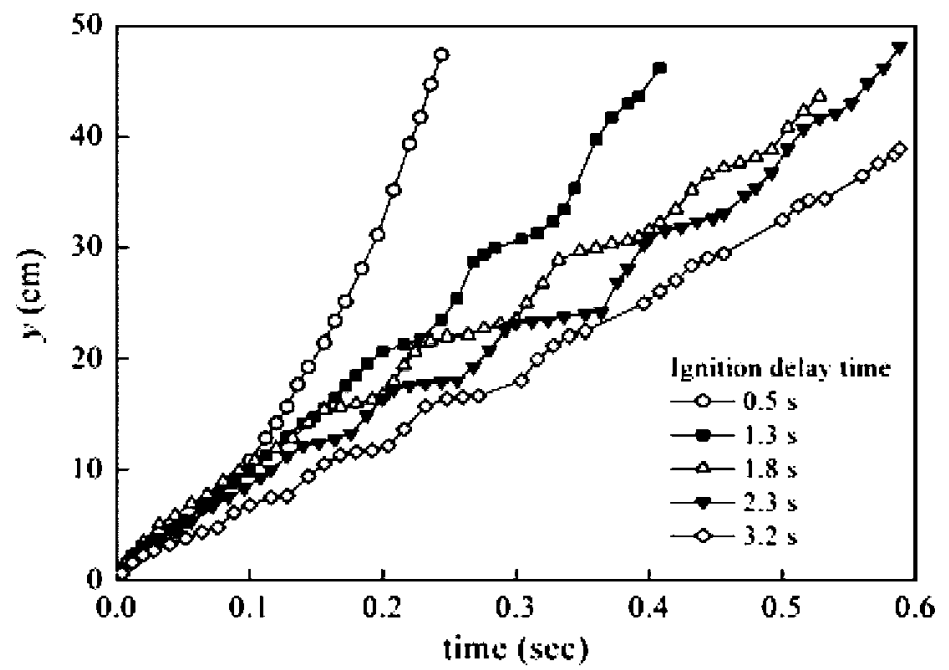

Figure 6. Displacement of flame front as a function of time (the duct closed at the bottom end and open at the top).

indicates that laminar flames fluctuate about a mean velocity, and in the stage when flame oscillations appear, the flame velocity varies with the characteristic frequency. The mean value of flame propagation velocity, represented by the average slope of $y$ against $t$, was found to range from 1 to $0.5 \mathrm{~m} / \mathrm{s}$, decreasing with increasing ignition delay time. In contrast, the turbulent flame undergoes obvious acceleration. At the upper end of the field of view, the flame velocity can be as high as $4 \mathrm{~m} / \mathrm{s}$. The burning velocity of both flames (laminar and turbulent) can be estimated in relation to the propagation velocity as a magnitude 5-6 times smaller (their order of magnitude may be expressed by a product of the propagation velocity and the density ratio of combustion gases to the fresh mixture).

In another case of flame propagation, from open bottom to closed top of the testing duct, the flame was raised upward by buoyancy. The calculated buoyant velocity appears to be $0.4 \mathrm{~m} / \mathrm{s}$ (see the Davies-Taylor formula in the paper of Jarosinski, 1986). Depending on the value of ignition delay time, two kinds of flames were also observed: laminar and turbulent. The typical laminar flames have been observed for delay times greater than $1.4 \mathrm{~s}$, while for $t_{i}$ less than $1.1 \mathrm{~s}$ the experimental conditions give rise to turbulent type flames. Examples of a laminar 
and a turbulent flame are shown in Figure 7. As can be seen, the appearance of the laminar flame is similar to that illustrated in Figures 5(a) and 5(b), and the turbulent flame similar to that in Figure 5(c). However, the flame oscillations in the duct as observed in the last case have vanished.

The shadow method can reveal more details of the flame structure. As an illustration, sequences of shadow records of propagating laminar and turbulent flames are reproduced in Figures 8(a) and 8(b). In these images, a narrow dark zone can be seen clearly ahead of the flame front, which roughly represents the preheat zone typical of the volatile type dust flames. The visualization of turbulent flames shows a very irregular distribution of regions with local reactions behind the flame front. As the time goes, the main flame front is notably stretched in the vertical direction so that it is separated from the following flames by increasing distance. This means that these flames propagate with different velocities, and the highest velocity is for the main flame. For laminar dust combustion, a few separated flames are also observed behind the main flame front, although they are much less visible than in turbulent flames because of more limited extent. It is evident from Figure 8 that the dust flames have complex structures in comparison with those in homogeneous gaseous mixtures. The multi-layer structure of dust flames suggests that the combustion takes place not ideally at a single flame front, instead it occurs at a cluster of surfaces where the gaseous

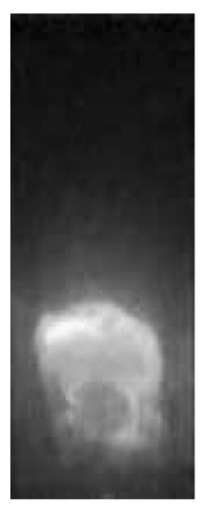

(a)

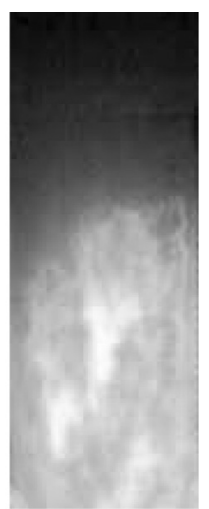

(b)

Figure 7. Photographs of typical cornstarch dust flames propagating from open bottom to closed top of the duct. (a) a laminar flame, $t_{i}=1.4 \mathrm{~s}$; (b) a turbulent flame, $t_{i}=0.6 \mathrm{~s}$. 

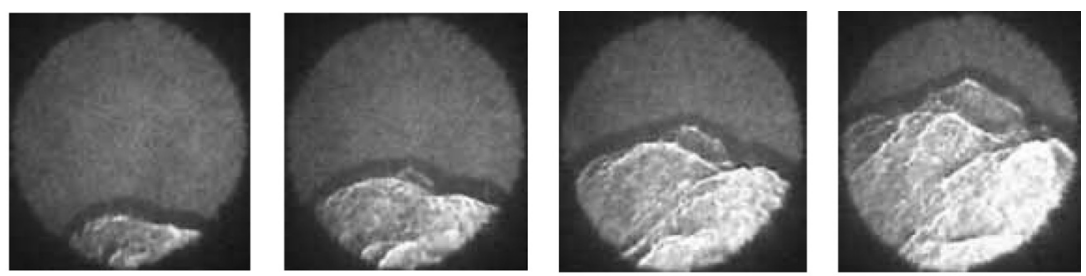

(a)
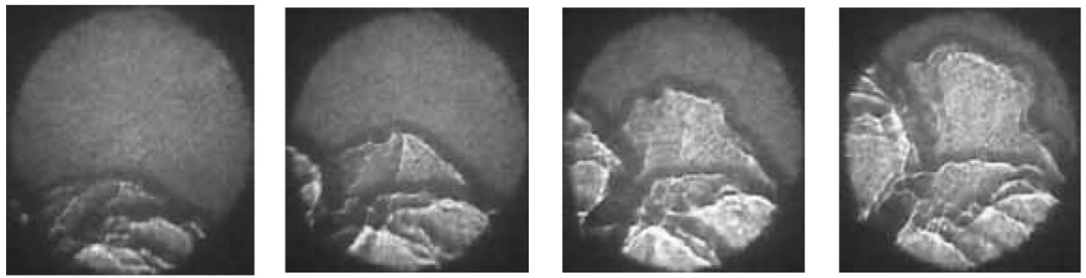

(b)

Figure 8. Shadow photographic records of cornstarch dust flame propagation from open bottom to closed top of the duct. (a) a laminar flame, time interval between pictures $0.012 \mathrm{~s}$; (b) a turbulent flame, time interval between pictures $0.012 \mathrm{~s}$.

decomposition of dust particles is available. Such information helps to explain the significant effects of dust particle distribution and turbulence on the combustion process.

Figure 9 shows the measured flame displacement as a function of time for $t_{i}=0.6,1.4,1.8$, and $3.2 \mathrm{~s}$ while the flame propagates from the open bottom end to the closed top end of the duct. Obviously, a linear relationship exists between $y$ and $t$ for all conditions of ignition delay time, indicating that the flames propagate with constant velocity in the duct. Thus the average slopes of flame coordinates in Figure 9 represent the propagation velocities, $W_{f}$. Results of such measurements are reported in Figure 10 as a function of the ignition delay time. It is interesting to notice that the variation of $W_{f}$ with $t_{i}$ has two regimes, and the transition occurs approximately at $t_{i}=1.1 \mathrm{~s}$. In the left regime (where turbulent propagating flames were observed), the flame velocity is as high as about $0.9 \mathrm{~m} / \mathrm{s}$. In the right propagation regime (laminar flames), the flame velocity is much lower $\left(W_{f}=0.45-0.56 \mathrm{~m} / \mathrm{s}\right)$ and does not vary much with the ignition delay time. Both for turbulent flames and for laminar flames, the propagation velocity is quite close to that reported by Proust and Veyssiere (1988) (for turbulent flames $W_{f} \approx 0.8 \mathrm{~m} / \mathrm{s}$, for laminar flames $W_{f}=0.45-0.63 \mathrm{~m} / \mathrm{s}$ ), although these authors $\operatorname{did}$ not 


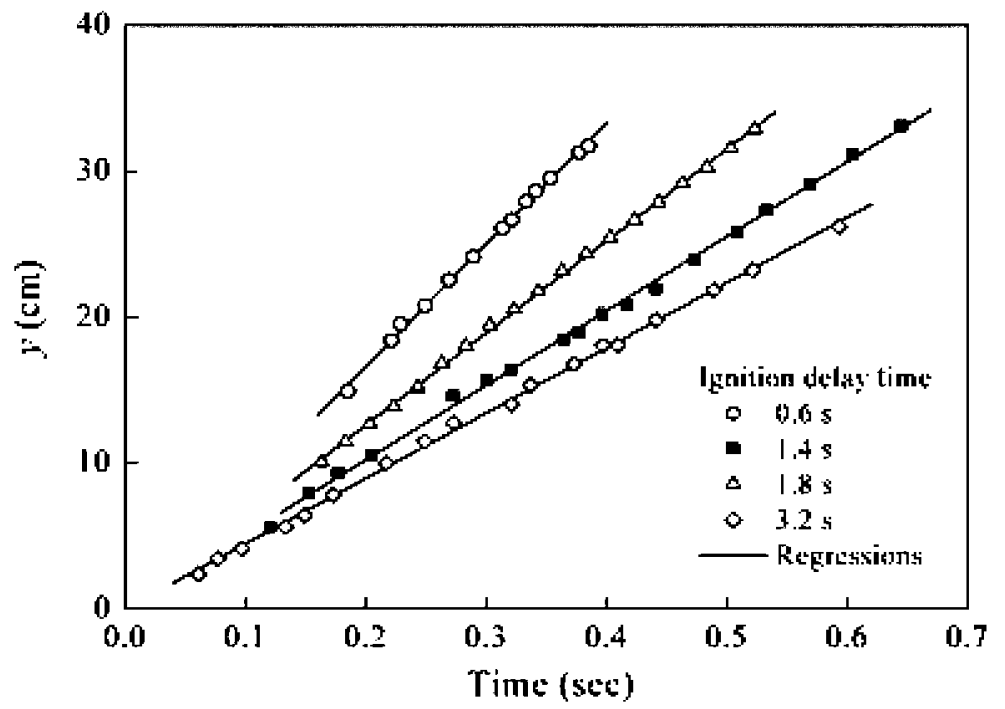

Figure 9. Displacement of flame front as a function of time (duct open at the bottom end and closed at the top).

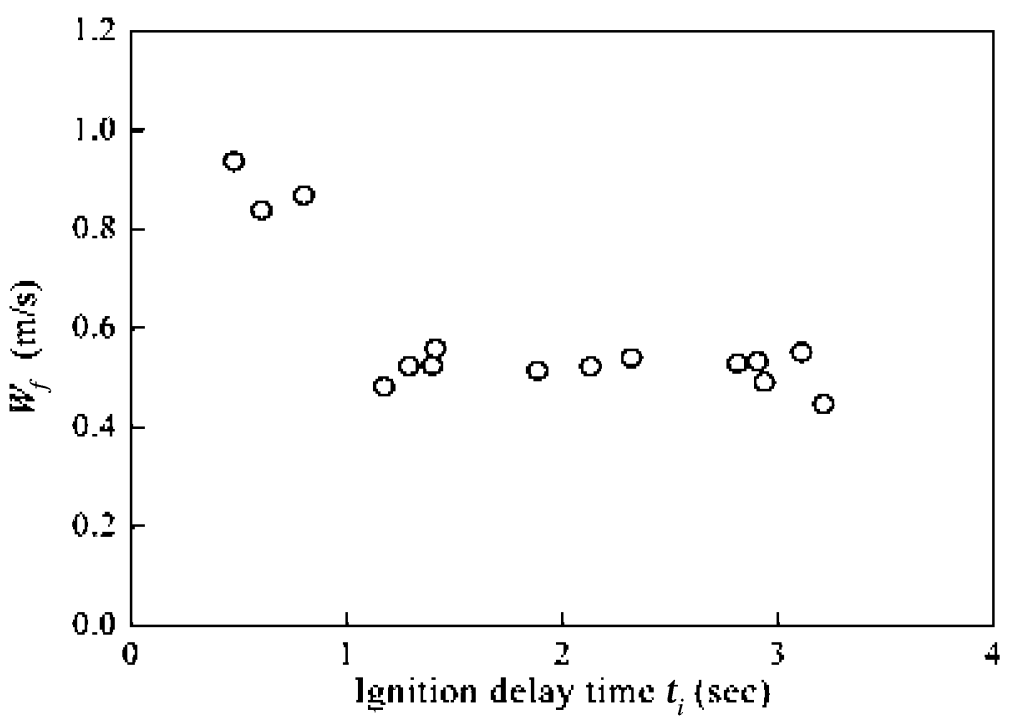

Figure 10. Variation of flame propagation velocity with ignition delay time (duct open at the bottom end and closed at the top). 
quantitatively assess the turbulence parameters in experimental dust clouds and determined the state (laminar or turbulent) of the clouds simply by observation.

As mentioned above, the dust concentration decreases considerably along the height of the duct, and yet the flame propagates upwards at a constant velocity. This observation may suggest that the dust concentration has little influence on flame propagation velocity. The observation of flame propagation regimes and the flame velocity data in Figure 10 have suggested that the ignition delay time determines the features of cornstarch dust flames propagating in the duct. Because the dust concentration is proven to be a factor of small influence in flame propagation under present experimental conditions, the change in flame behaviors with increasing delay time could be attributable to the decrease of turbulence intensity, i.e., the turbulence intensity can be regarded as an independent parameter to examine its influence. As a quantitative measure, one can decide that the transition from laminar to turbulent flames occurs close to the ignition delay time $1.1 \mathrm{~s}$. This critical condition, from the measurements of turbulence intensity, corresponds to a turbulence intensity of $8 \mathrm{~cm} / \mathrm{s}$ in the horizontal direction, and $11 \mathrm{~cm} / \mathrm{s}$ in the vertical direction. Since the ideal static and uniform dust cloud is impossible to realize under normal gravity conditions (Amyotte et al., 1989; Goroshin et al., 1996; Eckhoff, 1997), such a critical value of the turbulence level can serve as a practical condition to define the regime under which a laminar dust flame would be obtained. Certainly, the specific value of $10 \mathrm{~cm} / \mathrm{s}$ is preliminary, and should be justified through further investigation.

The curve shape in Figure 10 agrees with our expectation. The velocity of an upward propagating flame is a sum of the buoyant velocity and burning velocity. For laminar flames, this sum is dominated by the buoyant velocity. It is the reason why the flame velocity remains approximately constant for relatively high values of ignition delay time and corresponding to them low turbulence intensity [see Figure 3(a)]. When the ignition delay time is less than $1.1 \mathrm{~s}$, the flame is influenced by turbulence with higher turbulence intensity, and its propagation velocity can increase to $0.9 \mathrm{~m} / \mathrm{s}$. Most likely, the influence of turbulence on burning velocity can be explained by the relation of turbulence intensity to laminar burning velocity. The most probable value of laminar burning velocity of investigated cornstarch dust flames is $10 \mathrm{~cm} / \mathrm{s}$ or even less (Mazurkiewicz et al., 1993). It is evident from the present experimental results that a clear 
increase in the flame propagation velocity begins when the ratio of turbulence intensity to laminar burning velocity is more than 1 .

\section{SUMMARY}

The experimental study was conducted to elucidate the effects of small scale turbulence and small turbulence intensity on the flame propagation in cornstarch dust clouds. For this purpose, an improved dust dispersion mechanism was designed, and the resulting states of dust clouds were determined in a vertical duct of $780 \mathrm{~mm}$ height and $160 \times 160 \mathrm{~mm}$ square cross section. The feature of dispersion-induced turbulence, including turbulence intensity, integral scale and their variations with time was determined by means of a PIV measurement system and ensemble average method. Dust concentrations were measured by direct weighing method. The results show that the turbulence intensity induced by the dispersion process is less than $20 \mathrm{~cm} / \mathrm{s}$, much lower than those obtained with previous dispersion systems, and the decay of turbulence is slow. The integral scale of the turbulence increases with time from 2 to $3 \mathrm{~cm}$ during about $3 \mathrm{~s}$. The decrease of dust concentration with time is also slow, indicating that dust suspensions in air could be maintained during a relatively long period.

Based upon the dust dispersion apparatus, upward dust flame propagation was established in the duct, with the top end open and the bottom end closed (case A), or the top end closed and the bottom end open (case B). The flames were visualized with a high-speed camera and with the shadow method. With the increase of ignition delay time, two different kinds of flames were observed in both cases. In case A, they are turbulent flame, and laminar but oscillating flame; while in case B, they are turbulent and laminar flames. The transition occurs when the ignition delay time is about $1.1 \mathrm{~s}$, corresponding to a turbulence level of $10 \mathrm{~cm} / \mathrm{s}$. In both cases of flame propagation, the influence of turbulence on flame characteristics has very similar effect for the equivalent ignition delay times.

The flame propagating from the closed bottom end to the open top end of the duct was pushed upward by the expansion of hot combustion gases. The mean propagation velocity of laminar flames slightly decreased with the increase of ignition delay time (approximately from 1 to $0.5 \mathrm{~m} / \mathrm{s}$ ). The turbulent flame could accelerate to a velocity as high as $4 \mathrm{~m} / \mathrm{s}$. The burning velocity of both flames can be estimated in relation to the propagation velocity as a magnitude 5-6 times smaller. 
The flame propagating from the open bottom end to the closed top end of the duct was raised upward by buoyancy. The flame propagation velocity is a sum of the buoyant velocity and burning velocity. For relatively high values of ignition delay time (corresponding to low turbulence intensity), the flame velocity is dominated by the buoyant velocity, and remains approximately constant. When the ignition delay time is less than $1.1 \mathrm{~s}$, the flame is influenced by turbulence with higher turbulence intensity, and its velocity can increase to a value of $0.9 \mathrm{~m} / \mathrm{s}$. It was determined experimentally that the propagation velocity of laminar flames is in the range of $0.45-0.56 \mathrm{~m} / \mathrm{s}$, and that of turbulent ones takes the order of $0.9 \mathrm{~m} / \mathrm{s}$.

The observation of shadow images showed that the flame structure contains preheat and combustion zones typical of the volatile type dust flames. A very irregular distribution of separated flames was observed to occur behind the flame front, especially in turbulent combustion zones. Such heterogeneous feature indicated the importance of the state of dust clouds.

\section{REFERENCES}

Amyotte, P.R., Chippett, S., and Pegg, M.J. (1989) Effects of turbulence on dust explosions. Prog. Energy Combust. Sci., 14, 293-310.

Dreizin, E.L., Shoshin, Y.L., Mudryy, R.S., and Hoffmann, V.K. (2002) Constant pressure flames of aluminum and aluminum-magnesium mechanical alloy aerosols in microgravity. Combust. Flame, 130, 381-385.

Eckhoff, R.K. (1997) Dust Explosions in the Process Industries, 2nd ed., Butterworth-Heinemann, Oxford.

Goroshin, S., Bidabadi, M., and Lee, J.H. (1996) Quenching distance of laminar flame in aluminum dust clouds. Combust. Flame, 105, 147-160.

Han, O.-S., Yashima, M., Matsuda, T., Matsui, H., Miyake, A., and Ogawa, T. (2001) A study of flame propagation mechanisms in lycopodium dust clouds based on dust particles behavior. J. Loss Prev. Proc. Ind., 14, 153-160.

Hinze, J.O. (1975) Turbulence, 2nd ed., McGraw-Hill, New York.

Jarosinski, J. (1986) A survey of recent studies on flame extinction. Prog. Energy Combust. Sci., 12, 81-116.

Jarosinski, J., Lee, J.H., Knystautas, R., and Crowley, J.D. (1986) Quenching of dust-air flames. 21st Symposium (International) on Combustion, The Combustion Institute, 1917-1924.

Jarosinski, J., Pu, Y.K., Bulewicz, E.M., Kauffman, C.W., and Johnson, V.G. (1993) Some fundamental characteristics of cornstarch dust-air flames. Prog. Astronaut. Aeronaut., 152, 119-135. 
Jarosinski, J., Podfilipski, J., and Pu, Y.K. (2000) Visualization of dust explosion under microgravity conditions. Combust. Sci. Technol., 158, 183-194.

Krazinski, J.L., Buckius, R.O., and Krier, H. (1979) Coal dust flames: a review and development of a model for flame propagation. Prog. Energy. Combust. Sci., 5, 31-71.

Mazurkiewicz, J., Jarosinski, J., and Wolanski, P. (1993) Investigations of burning properties of cornstarch dust-air flames. Archivum Combustionis, 13, 189-201.

Proust, C. and Veyssiere, B. (1988) Fundamental properties of flame propagating in starch dust-air mixtures. Combust. Sci. Technol., 62, 149-172.

Pu, Y.K., Jarosinski, J., Tai, C.S., Kauffman, C.W., and Sichel, M. (1988) The investigation of the feature of dispersion-induced turbulence and its effects on dust explosions in closed vessels. 22nd Symposium (International) on Combustion, The Combustion Institute, 1777-1787.

Pu, Y.K., Li, Y.C., Kauffman, C.W., and Bernal, L.P. (1989) Determination of turbulence parameters in closed explosion vessels. Prog. Astronaut. Aeronaut., 132, 107-123.

Tamanini, F. and Chaffee, J.L. (1990) Turbulent unvented gas explosions under dynamic mixture injection conditions. 23rd Symposium (International) on Combustion, The Combustion Institute, 851-858. 